\author{
Military Technical College \\ Kobry El-Kobbah, \\ Cairo, Egypt.
}

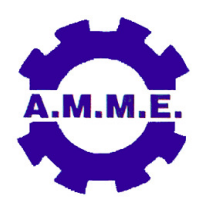

\title{
LAYOUT OF GRADUATE-LEVEL FLUID POWER RESEARCH LAB.
}

\author{
M. K. Bahr*
}

\begin{abstract}
Fluid power research works in the graduate level are growing in various educational institutions. Many of these institutions do not follow the proper methodological approach in building fluid power research lab. The fact is the fluid-power related research equipment are ordered as required piece-by-piece without long term planning, which may results in duplication of equipment and inefficient use of budgets and space.
\end{abstract}

Fluid power research lab should at least satisfy some fundamental needs for a researcher. In this seminar, the presenter will discuss the standard layout of fluid power research lab, the units must be included and the research roadmap that matches the proposed units.

* Director of Professional Education, Milwaukee School of Engineering, Chairman of Fluid Power Mathematical Modeling Committee, 1025 North Broadway, Milwaukee, WI, 53202-3109, USA. Email: khalil@msoe.edu. 